\title{
Peeling back the veil \\ A review of Stuart Cunningham. 2013: 'Hidden Innovation: Policy, Industry and the Creative Sector'
}

Trevor Barr

Swinburne University of Technology

\begin{abstract}
A review of Stuart Cunningham. 2013: 'Hidden Innovation: Policy, Industry and the Creative Sector'. Queensland University Press. ISBN 9780702249556
\end{abstract}

If a poll were conducted into the innovation considered to be Australia's most significant, the black box flight recorder invented by Australian David Warren in the 1950s might win it. This piece of equipment, which records the voices and instrument readings in the cockpit of an aircraft provides crucial aviation evidence for reconstruction. Yet not a single black box flight recorder has ever been manufactured in Australia. It's so often quoted as symptomatic of the Australian innovation problem - we are great at inventing things, but even better at giving them away to others for their commercial gain. Our consistent failure to transfer from the creation of a prototype, to the local manufacturing stage, and then to successful commercialisation, has tended to be the focal point of our analysis about innovation issues, problems and policies.

In Hidden Innovation: Policy, Industry and the Creative Sector, Stuart Cunningham, Director of the Australian Research Council Centre of Excellence for Creative Industries and Innovation (CCI), offers a new take on innovation from an entirely different perspective centred on the important role of the creative industries. He deconstructs a mythology that sees creative workers as typically self-indulgent members of the latte set living off government grants, who now vote for the Greens instead of Labor, and whose contributions to society are marginal at best! Cunningham makes a convincing set of arguments that the creative industries have neither been well understood, nor widely recognised, as major contributors to the economies of developed countries. His basic thesis is that the ideas, processes, and products within this sector of innovation have been crucial to driving productivity in Australia.

This book is written from the perspective of the director of an Australian ARC Centre of Excellence research organisation, the only such ARC research centre in the fields of arts, humanities and social sciences. Cunningham has constructed his innovation thesis drawing 
upon a wide range of interdisciplinary research findings. He deals with the elusiveness of the terminology 'the creative industries', their components, what constitutes a 'creative city', related international policy processes and he assesses how such programs have fared in practice. His most grounded sections deal with the different modes of creative production, and a chapter is devoted to the remarkable set of contemporary innovations that have emerged from public broadcasters. He offers good insights into the use of immersive experiences in Children's BBC programs, and canvasses the imaginative public health issues program Embarrassing Bodies offered by Britain's Channel Four. He does not offer the conclusion made by others that people within public and community broadcasting have been more innovative than their counterparts in the private sector, and achieved such with more limited resources during the past decade.

Many researchers have delved into the methodological minefield of how creative industries are defined, but Cunningham and other researchers began with data based on the Australian census of 2006 to show the two major categories of occupations that make up the creative economy:

- Cultural production - film, TV and radio; publishing; music; performing and visual arts, and

- Creative services - architecture and design; advertising and marketing; digital content and software.

These data shows that the two groups, together with their allied support industries, constituted 469,684 workers in 2006 , or $5.2 \%$ of the total national employment. Cunningham goes on to show that based upon later analysis by The Centre for International Economics, which updated $\mathrm{CCi}$ analysis of Australian census data, that over the eleven years to 2007-08 the creative industries expanded at an average growth rate of $5.8 \%$, compared with average GDP growth rate of $3.6 \%$ over the same period. And a later figure, based on 2011 data, is that 531,000 people constitutes an important $5.3 \%$ of the total work force. Note that these researchers have included as creative workers, with good reason, a portion of the support workers such as legal personnel, technicians and administrators. To make a comparison with another industry, Mitch Hooke, chief executive of the Minerals Council of Australia, put the total employment in the Australian coal industry at a mere 180,000 when attacking the Greens mining policy in 'Greens would milk mining dry' (The Australian, 1 August, 2013.) Such research by Cunningham into the so-rarely investigated creative industries is invaluable evidence in terms of working towards creating good policy. Notably the above data was cited in the well-considered national cultural policy document, Creative Australia, which emerged from Simon Crean's arts portfolio earlier this year. Cunningham's book does indeed 'peel back the veil' of the cynics as promised. 
Cunningham gives a succinct historical sweep of how economic growth can be attributed to innovation as far back as the industrial revolution of the nineteenth century. However, my let down as I read towards the end of this book was my hope of a big take away about bright prospects that we all might somehow build, and all agree upon, constructive national innovation policy for the future. I guess I was hoping for the policy leadership of Paul Keating to be applied here. That is, to somehow grab a hugely imaginative public policy idea, do the tough homework on its development, sell it publicly to get it really well understood, be prepared to take the flak from all sides and above all, stay the course.

We need a kind of innovation policy equivalent of Paul Keating's brilliant national superannuation scheme so widely heralded today. But it's grossly unfair to Stuart Cunningham alone to expect him to carry the load alone in a field with generally limited public understanding of the complexity of issues related to the creative industries and Australian innovation policy. Yet surely in the context of the debates that Australia has an urgent need to diversify its economic base because of its narrow dependence on the mining and resource sector, we must all look to the remarkable opportunities innovation can bring as part of our necessary re-think.

As I put down this valuable book I thought again of Dave Warren of the black box flight recorder fame who was listed among the 'Top 100 living geniuses' in 2007, (he died in 2010 aged 85), compiled by a panel of experts on creativity and innovation. Warren, who struggled for so long to get his work recognised, might well have said of this fine work by Stuart Cunningham 'I've seen this movie before!'

But we should all read the book. Highly recommended.

Cite this article as: Barr, Trevor. 2013. 'Peeling back the veil. A review of Stuart Cunningham. 2013: "Hidden Innovation: Policy, Industry and the Creative Sector" '. Australian Journal of Telecommunications and the Digital Economy 1 (1): pp.6.1 - 6.3. DOI: $10.7790 / a j t d e . v 1 \mathrm{n} 1.6$ Available at: http://telsoc.org/journal 